\title{
Intraoperative awake brain mapping and multimodal image-guided resection of dominant side insular glioma
}

\author{
*Zhengda Yu, MD, ${ }^{1}$ N. U. Farrukh Hameed, MBBS, MCh, ${ }^{1}$ Nan Zhang, MD, PhD, ${ }^{1}$ Bin Wu, MD, ${ }^{1}$ \\ Jie Zhang, MD, PhD, ${ }^{1}$ Junfeng Lu, MD, PhD, ${ }^{1}$ Tianming Qiu, MD, PhD, ${ }^{1}$ Dongxiao Zhuang, MD, PhD, ${ }^{1}$ \\ Hong Chen, MD, ${ }^{2}$ and Jinsong $\mathrm{Wu}, \mathrm{MD}, \mathrm{PhD}^{1}$ \\ Departments of ${ }^{1}$ Neurosurgery and ${ }^{2}$ Pathology, Huashan Hospital, Fudan University, Shanghai, China \\ Resection of insular tumors in the dominant hemisphere poses a significant risk of postoperative motor and language \\ deficits. The authors present a case in which intraoperative awake mapping and multi-modal imaging was used to help \\ preserve function while resecting a dominant insular glioma. The patient, a 55-year-old man, came to the clinic after \\ experiencing sudden onset of numbness in the right limbs for 4 months. Preoperative MRI revealed a nonenhancing le- \\ sion in the left insular lobe. Gross-total tumor resection was achieved through the transcortical approach, and the patient \\ recovered without language or motor deficits. Informed patient consent was obtained.
}

The video can be found here: https://youtu.be/gFky09ekmzw.

KEYWORDS insula; glioma; transcortical resection; video 